\title{
A New Approach to the Problem of Protection of Undermined Objects on the Earth's Surface
}

\author{
Sergey Kulibaba ${ }^{1}$, and Ekaterina Esina $^{1, *}$ \\ ${ }^{1}$ Institute of Comprehensive Exploitation of Mineral Resources Russian Academy of Sciences (IPKON \\ RAS), 111020, Moscow, 4, Kryukovsky tupik, Russian Federation
}

\begin{abstract}
Protection of undermined buildings, structures and natural objects on the earth's sur-face is to eliminate or minimize the hazardous effect of underground mining on their safe state and functioning. Based on the analysis of the provisions of the current regulatory document regulating the rules for the protection of objects on the earth's surface from the negative impact of mining operations, it was concluded that the method for determining the hazardous effect zones boundaries by means of shift angles in modern conditions of underground mining of stratified deposits is imperfect. A new approach to solving the problem of optimization of mining operations under built-up areas is proposed. This approach opens up a wide range of possible engineering solutions when planning the development of mining operations in the fields, and various options for protecting buildings, structures and natural objects located in the undermined areas.
\end{abstract}

\section{Introduction}

The depletion of mineral resources makes it necessary to involve in the operation of deposits at great depths, which occur in complex geological and geomechanical conditions. A special role is given to the problem of integrated development of reserves and rational planning of mining operations [1-5]. It should be noted that significant reserves of minerals left in the safety pillars under the protected objects on the earth's surface, the dimensions of which increase proportionally with depth. Leaving pillars insufficient size can lead to loss of the load-bearing capacity of the array and the development of emergency situations [6-12]. On the other hand, leaving pillars inflated size is forever left in the depths of mineral reserves. In this regard, the determination of the optimal size of the targets for the protection of the worked-out objects determines the safety and efficiency of mineral reserves development [13-14].

\section{Disadvantages of the existing method}

Protection of undermined buildings, structures and natural objects on the earth's surface is to eliminate or minimize the hazardous effect of underground mining on their safe state and functioning. The regulatory document being valid in the coal industry of the Russian Federation [15], determining the boundaries of hazardous effect zones of underground works

\footnotetext{
* Corresponding author: esina555@list.ru
} 
on these objects, with use of the so-called criterion method, that is use of critical values of the earth's surface deformations (inclination $i=4 \times 10^{-3}$, curvature $K=0,2 \times 10^{-3} 1 / \mathrm{m}$, relative horizontal tension $\varepsilon=2 \times 10^{-3}$ ). Using the same criteria, defined in previous periods, the values of the shift angles for the main coal-mining regions were determined, which are used up to the present time to define the boundaries of hazardous effect. Thus, it is assumed that when forecasting the localization of such a zone over the planned stope, the lines drawn from its boundaries along the shift angles will cross the earth's surface at the points where the abovementioned critical deformations are expected.

When the conditions of undermining change, for example, with increasing its depth or decreasing the extracted seam thickness, this approach ceases to be valid since in this case the actual deformations of the earth's surface corresponding to the critical values shift towards the centre of the trough, and the shift angles built on this principle become steeper than their normative values. The same effect is observed when determining the boundary angles necessary for determining the boundaries of the shift trough where the criterion method is also used.

Consider this effect on the example of determining the shift angles based on the inclination of the earth's surface $i$. Fig. 1 shows graphs of these deformations on a structure section along a course of seam for two different cases $I$ and $I I$, differing from each other in the extraction height of the working seam. In the first case (solid curve), with a greater value of thickness, the critical value of the inclination, equal to $4 \times 10^{-3}$, is localized at the point $I$ of the earth's surface, located at a distance $L_{I}$ from the point $A$ of the maximum height reduction of the considered half-trough $\mathrm{AB}$, and the shift angle $\delta_{I}$ according to [15] is defined by the straight line $C-I$. In the second case (dotted line), at a lower thickness, the earth's surface plot with the same value $i=4 \times 10^{-3}$ moves from point $I$ to point $I I$, located at a distance $L_{I I}$ from point $A$; accordingly, the shift angle in this case will be determined by the straight line $C$ - $I I$, and its value will be $\delta_{I I}$. Obviously, a decrease in the extracting seam thickness under other equal conditions will cause an increase in the value of the shift angle by an amount of $\Delta \delta_{\text {I-II }}=\delta_{\text {II }}-\delta_{\text {I }}$, and a decrease in the size of the hazardous effect zone in the considered shift half-trough by an amount of $\Delta \mathrm{L}=\mathrm{L}_{\mathrm{I}}-\mathrm{L}_{\mathrm{II}}$ (see Fig.1).

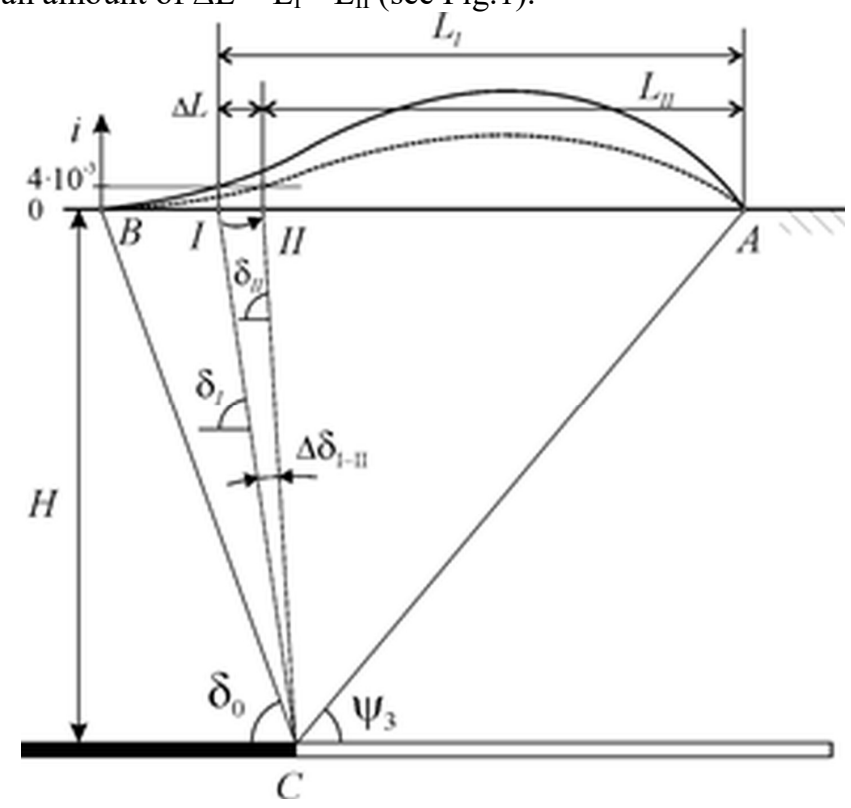

Fig. 1. Graphs of earth's surface inclinations $i$ on a structure section along the strike. 
A similar effect is observed with increasing the mining depth, as a result of which the earth's surface deformations also decrease, not only the inclines, but also the relative horizontal deformations and the curvature, thereby reducing the size of the hazardous effect zone.

Thus, we can conclude that the actual shift angles defined by criterion method may deviate from the values regulated by the "Rules of protection..." [15]. Calculations of the expected shifts and deformations of the earth's surface for the underground mining of coal seams for the characteristic conditions of the Kuzbass mines allow estimating the degree of such a deviation. Fig. 2 shows the graphs of change of differences $\Delta \delta=\delta_{\mathrm{i}}-\delta$, where $\delta_{\mathrm{i}}$ is the shift angle determined by the criterion method, $\delta$ is the shift angle for the considered conditions equal to $80^{\circ}$. Analysis of the graphs shows that a complete coincidence of the values of real shift angles with normative $(\Delta \delta=0)$ at different thickness values of the working seams is observed in the depth interval $100-200 \mathrm{~m}$. With increasing the mining depth, the difference increases, reaching values of $8-13^{\circ}$ at a depth of $600 \mathrm{~m}$, which leads to a significant change in the hazardous effect boundary location being determined, in tens and hundreds of meters.

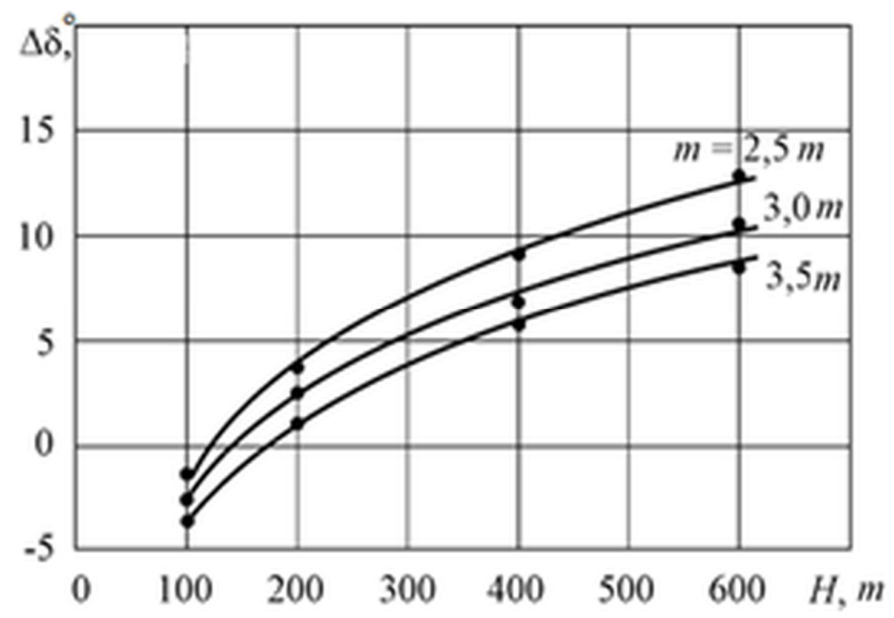

Fig. 2. Graphs of the change in the deviation of the shift angle $\delta$ determined by the criterion method, from the normative value.

In other words, the actual shift angles that limit the hazardous effect zones of mine workings on the earth's surface and are defined by the values of critical deformations according to the current "Rules of protection ..." [15] are not constant values, and under modern conditions of underground mining of coal seams do not coincide with their normative values.

The main mining measure for the protection of buildings, structures and natural objects from the impact of mining in domestic practice is leaving high pillars in the working seams. For most of protected objects, the borders of this pillar separating permitted and prohibited for mining seam plots, are determined by means of the shift angles. Thus, it is assumed that if mining works are carried out outside the pillar, the protected object will be protected from the negative impact of the shift process and will retain all its operational capabilities. At the same time, there are a number of objects for which permissible and sometimes even limit deformations are much less than the critical values for which the shift angles are defined (crane runways, some equipment of rolling mills and pipe-making shops, industrial furnaces, 
pipelines, etc.). Therefore, even being under the protection of the pillar, these structures may be deformed, capable of causing a violation of their operational capabilities.

\section{New method of protection of undermined objects on the Earth's surface}

Summarizing the above facts, it can be concluded that in the present conditions of stratified mineral deposits underground mining, the existing approach to the problem of protecting the undermined objects on the earth's surface with the use of shift angles has lost its relevance, since it does not imply an unambiguous solution. On the one hand, the change of mining conditions affect the magnitude of the shift angles which become steeper with the formation depth, on the other hand, the pillars constructed according to the normative values of the shift angles do not always provide full protection of the objects. While in the first case, pillars of unreasonably high size are left to protect the objects which leads to irreplaceable, as a rule, losses in the mineral resources, in the second case there is a risk of deformations and violations to protected objects.

Thus, it can be concluded that in modern conditions of sheet deposits underground mining, the use of shift angles, both for determining hazardous zones on the earth's surface, and for constructing high pillars for protected objects, becomes meaningless.

In our view, one of the most promising ways out from the current situation is to change the conceptual approach to the problem of undermined objects protection. The main provisions of the new approach are as follows:

- rejection of the shift angles as a tool for constructing high pillars and determining with their use hazardous effect zones of underground mining for protected objects;

- allocation in the working seam of the zone affecting the object which requires protection from the harmful effect of pillar mining, the boundaries of which are determined by the boundary shift angles;

- prediction for the earth's surface shift from the stope scheduled for mining within this zone of influence, and making the decision on the permissibility of undermining based on the comparison of the expected (estimated) deformation values with the permissible (limit) values for the protected object.

\section{Conclusions}

This approach opens up a wide range of possible engineering solutions when planning the development of mining operations in the fields, and various options for protecting buildings, structures and natural objects located in the undermined areas. Based on the results of the forecast, for example, it will be possible to vary the size of the high pillars depending on the available means and possibilities for organizing constructive and/or mining protection measures for protecting the objects, up to their complete undermining, which ultimately optimizes the process of extracting the mineral from the subsoil under built-up areas.

\section{References}

1. M.P. Vasilchuk, K.N. Trubetskoy, A.M. Ilin, V.S. Zimich, V. A. Chanturiya, Mining journal, 7, 17 (1995)

2. K.N. Trubetskoy, S.V. Kornilkov, V.L. Yakovlev, Mining journal, 2, 15 (2012)

3. D.R. Kaplunov, D.N. Radchenko, Mining journal, 5, 28 (2016) 
4. D.R. Kaplunov, M.V. Rylnikova, D.N. Radchenko, Sustainable development of mountain areas, 3:25, 46 (2015)

5. K.N. Trubetskoy, D.R. Kaplunov, M.V. Rylnikova, Journal of Mining Science, 48:4, 688 (2012)

6. A.B. Makarov, D.V. Mosyakin, A.I. Ananin, Mining journal, 3, 32 (2017)

7. J.M. Galvin, Ground Engineering - Principles and Practices for Underground Coal Mining (Springer International Publishing, New York, 2016)

8. Z.T. Bieniawski, Engineering rock mass classifications: a complete manual for engineers and geologists in mining (John Wiley \& Sons, New York, 1989)

9. E. Hoek, T.G. Carter, M.S. Diederichs, ARMA, 672, 8 (2013)

10. D.H. Laubscher, JS Afr. Inst. Min. Metall, 90:10, 257 (1990)

11. J.M. Galvin, Ground Engineering -Principles and Practices for Underground Coal Mining. (Springer International Publishing, Switzerland, 2016)

12. M.C. Betournay, Proceedings of the 5th Biennial Workshop on Abandoned Underground Mines, Tucson, Arizona \& U. S. Department of Transportation, 133 (2004)

13. J.N. Van der Merwe, B.J. Madden, Rock Engineering for Underground Coal Mining. (SAIMM, New York, 2013)

14. Rules of protection of structures and natural objects from the harmful effects of underground mining on coal deposits (VNIMI, Saint-Petersburg, 1998) 